\title{
Do Competency Frameworks Influence Business Performance? An Empirical Study of the Nigerian Banking Sector
}

\author{
Kalama Adefe, Sunderland Business School \\ Derek Watson, Sunderland Business School \\ Joyce Liddle, Newcastle Business School
}

\begin{abstract}
The competency-based management system has grown to become one of the most influential HRM tools of the 21st century. However, there remains limited empirical data addressing the relationship between the adoption of a competency framework and organizational performance. The study reported upon in this paper is based within the Nigerian banking sector. A qualitative methodological approach was adopted, employing interviews with employees of the top ten high street banks in Nigeria. The result of the field data was subsequently analyzed using NVivo in order to achieve the aim of the research. The findings revealed that competency-based management frameworks are being used and that indeed they are a key management tool within the selected Nigerian banks. Importantly, the findings clearly suggest the adopted competency frameworks are having a positive impact on the banks' performance.
\end{abstract}

Key Words: competency, competency framework, HR systems, performance, banking, Nigeria.

\section{Introduction}

This study was designed to investigate the effect of competency framework on the performance of selected Nigerian banks. The competency-based management system has grown to become one of the most influential human resource management (HRM) tools of the 21 st century. Current global trends such as economic pressure, changes in technology, and customer demands have made it important for organizations to develop competencies (Mohd Noor \& Dola, 2009). As a result, many public and private organizations are now moving towards the competency-based HRM systems in order to meet these needs. Furthermore Australia, Britain, and the United States have utilized workplace competencies as a baseline and developed wide-ranging competency frameworks. The development of the competency framework in these countries was driven by the concern of workplace changes and enhancing the generic skills that the employers required (Kearns, 2001).

\section{Competencies, Competency Frameworks and Organizational Performance}

Competencies are defined as the "behaviours that an individual needs to demonstrate" or the "minimum standards of performance" (Strebler et al., 1997) that are significantly related to successful job performance (June \& Mahmood, 2011). Alternatively, competency standards determine the essential skills and knowledge that the employees should have to achieve acceptable 
level of performance (Draganidis \& Mentzas, 2006). Selznick (1957) and McClelland (1973) explained the key factors of competencies emphasizing an individual's learning and performance. The term 'competency' can be confusing. This is mainly because it has often been used to mean or particularly mixed up with 'skill' (CIPD, 2016). From the management viewpoint, the term competency is defined using two key streams: organizational or personal. McClelland (1973) used the term competency as a means to test for an alternative approach to traditional intelligence testing (McClelland, 1973). According to McClelland (1973), competence is a character trait of an individual that is linked to superior performance. This character trait is a demonstration of specific individual talents exhibited in line with the knowledge required to be successful in a job (McClelland, 1973). Competencies are also defined as a cluster of related knowledge, skills, and attitudes that affects the key parts of one's job that relates to performance. The performance can be measured against well-accepted standards and can be improved through training and development (Misra \& Sharma, 2017). Competencies are also viewed broadly and include many other factors that influence job success but are not included in the job description. A competency framework is a valuable means of measurement which helps employees understand and interpret the strategies, goals and values of the organization (Chouhan \& Srivastava, 2014).

Organizations can achieve their performance objectives through various factors, and one key factor is the human factor. In order to direct these human behaviours towards achieving the performance objectives of the organization, it requires a human resource management system that intentionally develops and supports the desired behaviours. Hence, various organizations have developed their own competency frameworks to help them identify the essential knowledge, skills, and attributes needed for successful performance in a particular job role, aligned with the strategy and integrating it to the HR strategy (CIPD, 2016). There is limited evidence that examines the relationship between competencies, competency framework, and organizational performance and certainly within the Nigerian banking sector. It is useful, nonetheless to highlight a number of studies which have sought, generally speaking, to address the relationship between HR systems (and thus implicitly addressing competency frameworks).

Huselid (1995) argued at a general level that HR practices could help create a source of competitive advantage, particularly if they are aligned with the organisation's competitive strategy (Huselid 1995). Koch and McGrath (1996) took a similar logic in their study of the relationship between HR planning, recruitment, staffing practices and labour productivity (Koch \& McGrath, 1996). They argued that, "A highly productive workforce is likely to have attributes that make it a particularly valuable strategic asset". In consequence, they suggested that organizations that develop effective routines for acquiring human assets develop a stock of talent not easily imitated (Koch \& McGrath, 1996). Furthermore, they found that these HR practices were related to labour productivity in a sample of business units and that this relationship was stronger in capital-intensive organizations (Lin \& Tang, 2016). Lepak and Snell (1999) asked executives to describe the HR systems that existed for jobs that represented particular quadrants of their model and found considerable support for the idea that the value and uniqueness of skills are associated with different types of HR systems within the same organization (Lepak \& Snell, 1999). These results were mostly consistent with the Lepak and Snell (1999) model and supported the basic proposition that diverse HR strategies exist within business. Boxall et al. (2007) examining the differential effects of HR practices on human capital, social capital, and organizational capital indicate that intensive/extensive staffing, competitive pay, intensive/extensive training, and promotion from within were most important for distinguishing high levels of human capital in organizations. 
Lawler and Mohrman (2003) suggested that the objectives of performance management systems often include the motivation of staff performance, assisting individual employees to develop their skills and abilities, creating a performance based culture, performance based promotion, identifying and eliminating poor performance, and supporting the implementation of the organization's strategy (Boxall et al., 2007). In consequence, performance management systems are designed to ensure that: the duties performed by the organization's workforce achieve the goals of the organization; the employees have a faultless understanding of their performance expectations; the employees receive continuous information on improving the effectiveness of their performance and what is expected of them; employee rewards commemorate employee performance; identifies developmental needs (Boxall et al., 2007).

\section{Methodology}

In order to achieve the aim of this study, the central research question investigated in this study was "Have competency frameworks influenced the performance of Nigerian banks?" To answer this research question, four key research objectives were created and answered using the qualitative interview. The four key research objectives that underpin the above research questions are as follows:

- Research Objective 1: To investigate the existing competency frameworks in the selected Nigerian banks.

- Research Objective 2: To examine the management consistency of the competency framework, and whom the framework applies to within the banks.

- Research Objective 3: To examine the alignment of the competency framework with the banks' HRM systems and processes.

- Research Objective 4: To investigate the influence of competency framework on the performance of the selected banks.

In order to answer the research question, one employee from each of the three levels was interviewed, representing senior level, mid-level and lower-level management. The researcher interviewed HR managers, senior managers such as director of operations, and banking officers who were directly involved with the competency framework as regards its design, usage or application. The interviewees were individuals who were familiar, knowledgeable, and experienced with the competency frameworks and thus had the potential to offer valuable information needed by the researcher to achieve the research aim (Rubin \& Rubin, 2005). Ten high street banks were selected for this study out of a total of 25 high street banks in Nigeria. The ten banks for this study were selected because they were classified as the top 10 commercial banks in Nigeria by KPMG in 2014. The scope of the KPMG 2014 survey covered 28 cities in 27 states across Nigeria in which they spoke to 20,770 retail-banking customers, 3,500 SMEs and about 400 corporate/commercial organizations. Their survey reflected the perspectives of the customer's levels of satisfaction and expectations from their banks.

A total of 30 qualitative semi-structured interviews were conducted with employees from the 10 selected banks. Each interviewee was interviewed once and the interviews lasted between 40 minutes and one hour. The qualitative interview data was subsequently analyzed using Nvivo in order to achieve the aim of the research. Nvivo is a specially developed computer aided 
qualitative data analysis system (CAQDAS) which is recognized as a highly reputable tool for managing and supporting qualitative analytical work. The data revealed that all the selected banks focused on a core competency framework, as forming the basis for their strategic direction. It was something they considered they did better than their competitors.

A model of the competency process used by the 10 banks is illustrated in Figure 1. This process is used to define and identify key features (knowledge, skills, and behaviour attributes) that the bank considers significantly important to effectively perform in a particular job role or an identified process. The process is used to assess competencies in order to achieve the bank goals. The model provided the researcher with a structured framework for investigating the research questions and hence guiding and informing the interview questions.

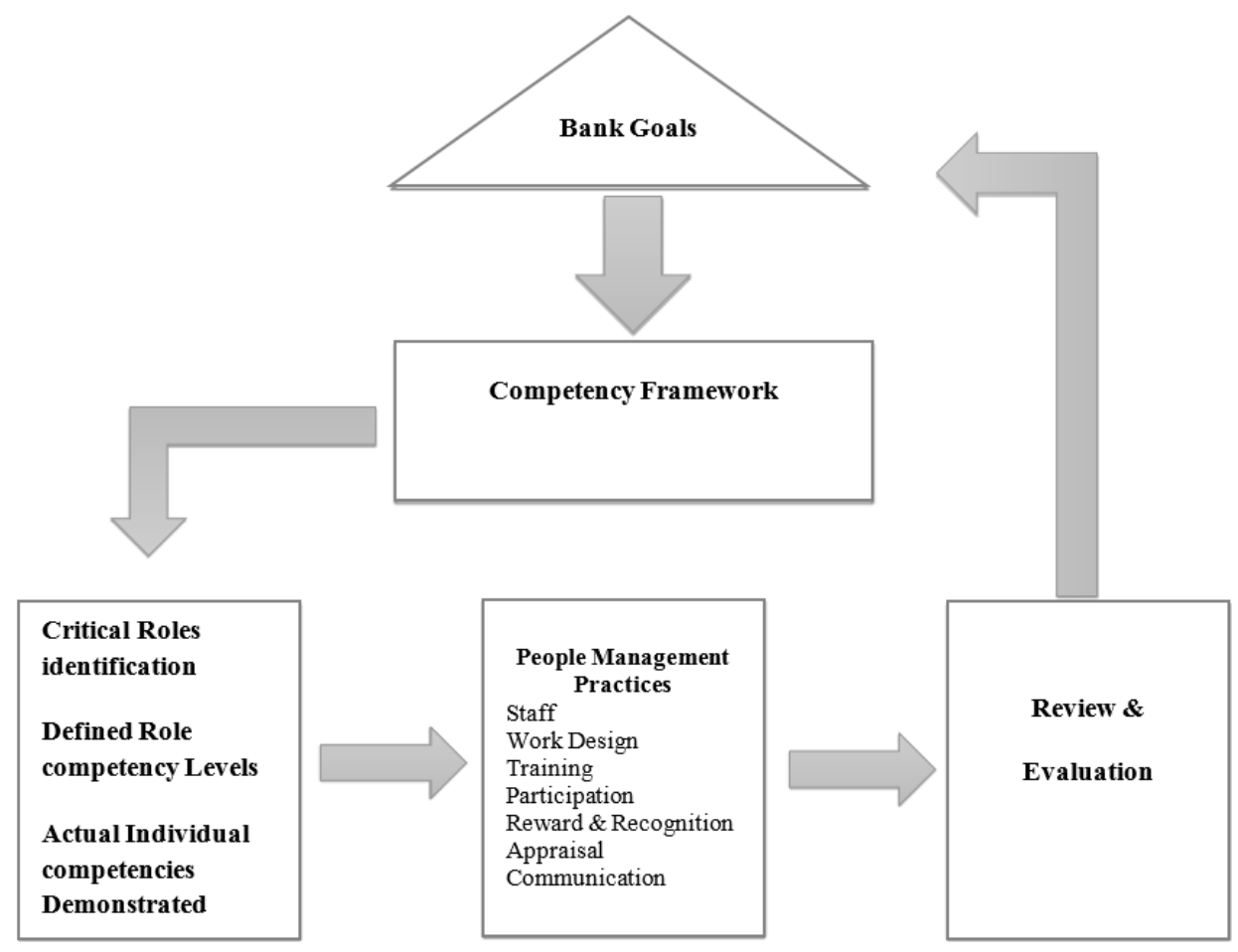

Fig 1: The Competency Process

\section{Discussion of Findings}

Previous academic research argued that competency frameworks can positively influence organizational performance. This study provides evidence in support of these claims in relations to Nigerian banks.

The first research objective of this study investigated the nature of the competency framework in the selected banks, the definition of the framework, application and implementation of the 
competency framework. This was achieved by analyzing both primary and secondary data from the selected banks. Secondary data sourced from the banks was also utilized to check the availability of the competency framework to see whom they applied to and cover, how they are implemented, and what the strategic human resource management (SHRM) coverage was within the selected banks. This corroborated the findings from the primary data and also informed the consistence with the literature. The data revealed the competency framework describes the skills and attributes staff and managers need in order to build a new organizational culture and meet the future challenges of the selected banks. Illustrative comments from respondents are noted in Tables 1 (Research Objective 1), 2 (Research Objectives 2 and 3) and 3 (Research Objective 4.).

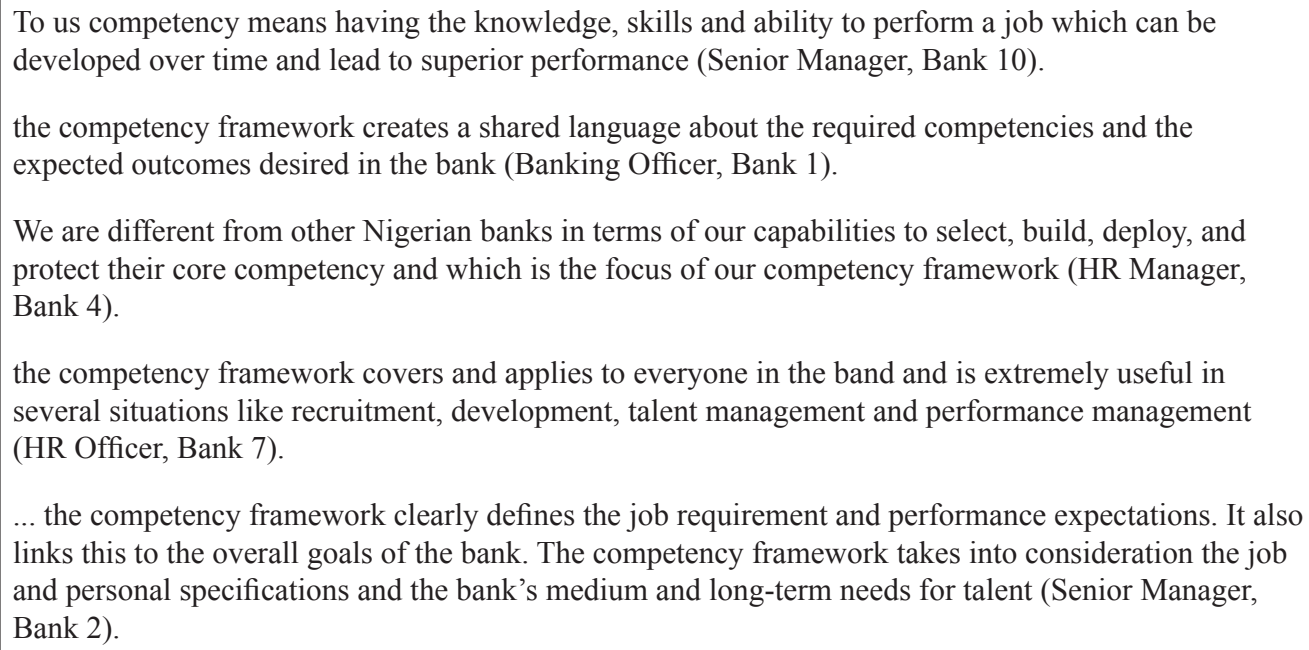

We are different from other Nigerian banks in terms of our capabilities to select, build, deploy, and protect their core competency and which is the focus of our competency framework (HR Manager, Bank 4).

the competency framework covers and applies to everyone in the band and is extremely useful in several situations like recruitment, development, talent management and performance management (HR Officer, Bank 7).

... the competency framework clearly defines the job requirement and performance expectations. It also links this to the overall goals of the bank. The competency framework takes into consideration the job and personal specifications and the bank's medium and long-term needs for talent (Senior Manager, Bank 2).

Table 1: Positioning the Competency Frameworks

As regards the positioning of the competency frameworks within the banks the findings reveal that the competency framework helps the selected banks to clarify expectations, define future development needs, and achieve more focused recruitment and development process in the banks as suggested by the CIPD (2016). However, there are gaps that exist in the data because it does not provide details of the frequency in which the competency framework is applied, evidence of examples on how it is infused into employee work, training, development, performance, and appraisals systems.

The second and third research objectives investigated the application and management of the competency framework within the SHRM systems of the selected banks, exploring consistency and alignment. This enabled the researcher to determine the length and breadth of the coverage of the competency framework in the selected bank, the depth of the framework in other HR systems of the banks in terms of performance, evaluation, training, development, and career progression. The data, illustrated in Table 2, shows there is a link between the strategic planning of the bank and the human resource planning of the bank.

Researchers have emphasized the need for HR function to bring in the strategic value of people in the organization by making a contribution to the level of value added and contribution to competitive advantage (Kelliher \& Perret, 2001; Calicchio \& Marcondes, 2016). The findings from this study supports this view and provides evidence in support of this assertion. 
The application of the banks SHRM in the competency framework is far reaching as it is well integrated in all our policies which are interpreted in our systems and processes (Senior Manager, Bank 10).

Our bank relies on the competency framework because it provides clarity and understanding of performance expectation which helps the bank cope with the changing environment, and the need to integrate our human resource strategy and our business strategy (Banking Officer, Bank 6).

Our competency framework enables us as a bank to align and integrate all our HR systems by making the behavioural standards of excellent performers the foundation for our recruitment, selection, performance management, pay, training and development and promotion. This makes it possible for us to come up with strategic decisions that have positive long-term impact on the behaviour and success of our bank and ensuring that the bank has the skilled, commitment and well-motivated employees needed to achieve our business objectives (HR Manager, Bank 1).

For us because human capital is our major focus so what we do or try to achieve is that from the recruitment process to exiting the bank there is some sort of initiative developed to enhance performance. Besides the regular HR function the HR department also manages the business because we have a business partner model where HR executives can become part of the business. The competency framework has always been a part of our SHRM and it is evidence in all we do as a bank from staff employment to exiting the bank (HR Manager Bank 8).

Our competency framework helps us to measure employees against a number of competencies, and individual strengths and weaknesses identified by the system provide opportunity for future development to be identified and executed (Senior Manager, Bank 3).

Our competency framework provides an effective HRM strategy that systematically organizes the entire individual HRM measures to directly influence the attitude and behaviour of our employees in a way that enables the bank to achieve its desired business goals (HR Manager, Bank 9).

Table 2: The Competency Frameworks Within the HR System

Research objective four investigated the influence of a competency framework on the performance of the selected banks in order to understand the interactions between competency frameworks and performance in the selected banks. To understand this relationship, the researcher investigated the position of reporting and evaluating performance.

This data (illustrated in Table 3) reveals a positive relationship between the competency framework and the performance of the selected banks.

\section{Key Findings from this Study}

The findings from this study revealed that a competency framework covers everyone in the individual banks and the evaluation of the framework is consistently applied in the bank during the annual staff appraisal period, and that the framework is evaluated to ensure it is fit for purpose. This is because the concept of competency lies at the heart of their Human Resource Management systems. This provides the basis for horizontal integration of key HR activities, such as selection, performance assessment, training, career development, and reward management, as well as vertical integration with organizational strategy, values, business processes, and performance outcomes among others. 
Our competency framework is proving to be a priceless resource for the banks as it helps us to define what is required of employees to perform successfully (HR Officer, Bank 2).

Our bank has a strong competency - performance relationship. This is because the outcomes of our evaluation processes are reported in the competency framework and used to improve our workforce and measure our leadership capabilities to improve performance (HR Manager, Bank 8).

The competency framework encourages us employees to take more responsibilities for our own development in order to perform better because the framework provides clarity on key areas and levels of performance expected by the bank (Banking Officer, Bank 1).

Increased and consistent application of the competency framework across the bank's human resource functions is driving our staff performance and has achieved results that are relevant to the bank's business strategies and vision. This is achieved by communicating the required competencies to employees, therefore, empowering the employees to take charge of their careers; direct their own personal development and continually evaluate and improve their skills (Senior Manager Bank 1).

There is an annual appraisal system in our bank and it has different levels of objectives which are frequently reviewed. We also have a financial target from the position of the business, and other nonfinancial targets in place to ensure that people stick closely and align with the bank's goals. The nonfinancial target corresponds with the culture of the banks and deals with the model of competencies associated with the development activities of individuals and teams. Our employees are very excited about the competency framework and believe it is leading to positive outcomes in the bank. This is because the bank's competency framework focuses on communicating and promoting a clear strategic goal that is embedded in the bank's HR systems and processes in order to achieve our performance objectives. (Senior Manager, Bank 5).

The bank's competency framework is relevant to our performance expectations and is used in a business relevant way. We have a management team tasked with the responsibility of making sure the competency framework is managed and evaluated regularly to make sure if it is fit for purpose and achieving our performance needs (HR Officer, Bank 3).

Our competency framework is an important vehicle for the bank to drive high business performance by focusing and reviewing each individual's ability and potential against expected performance outcomes (Senior Manager, Bank 9).

Table 3: Impact upon Performance

The data also reveals the existence of a link between the competency framework and the bank's SHRM strategy, the way they are used in the banks to attract and retain employees, how they inform key decisions on pay, and how it is linked to employee development. However, the data does not reveal the extent to which the banks have been able to achieve the competencyperformance relationship and how mature the bank's SHRM strategy aligns to the competency framework. This reduces somewhat the confidence we have about what is going on in the selected banks and how secure the competency SHRM link is within the selected banks in terms of performance.

Nonetheless, the data does reveal that the competency framework is influencing the performance of the selected banks, and the performance expectation of these banks. The combination of knowledge, skills and other personal characteristics that are necessary for the effective performance of the bank is included in the competency framework. The information and documents provided by the individual banks revealed that their bank's strategic approach to 
achieving their financial objectives is to leverage on the core competencies of the banks. Once the desired goals and objectives are defined, the bank identifies the job roles and employees critical to achieving these set goals and objectives.

The competency framework is used to define the competencies needed by the employees for each job role and function. It is also supported by the bank's people management functions, which include staffing, training, work design, reward, and appraisals. According to the data, the effectiveness of the bank's people management underpins and supports the bank's core competencies, which gives the bank an edge over rival banks. Based on this approach on achieving the bank's goals, findings revealed that competencies play a significant role in influencing the performance of the banks.

\section{Conclusion}

This study reveals that competency frameworks in the selected Nigerian banks do influence the performance of these banks. A key implication for the banks in this study is that they should continue to deploy their competency framework and indeed take steps to further develop and apply this aspect of HRD practice in order to consolidate efforts towards high performance working. For other banks in Nigeria and indeed, organizations in Nigeria more widely, the study offers evidence of an HRD practice that can help organizations improve their performance and assist them achieve their aspirations and goals. From a theoretical perspective, the results from this research deepen the analysis of the relationship between employee competency and performance. From the practical perspective, investing in employee competencies and developing their competencies is profitable to the business, as they will contribute to higher performance standards.

\section{References}

Boxall, P., Purcell, J., \& Wright, P. (2007). Human resource management: scope, analysis, and significance. The Oxford Handbook of Human Resource Management, p.1.

Boyatzis, R. E. (1982). The Competent Manager: A Model for Effective Performance. New York: John Wiley \& Sons.

Calicchio, A. C., \& Marcondes, R. C. (2016). Relevant factors for competitiveness in information technology consulting businesses. Gestão \& Produção, 23(3), 625-637.

Chouhan, V. S., \& Srivastava, S. (2014). Understanding Competencies and Competency Modeling - A Literature Survey IOSR Journal of Business and Management (IOSR-JBM) 16(1), 14-22.

CIPD (2016). Competency and competency framework. An examination of the history, principles and current practices around competency frameworks. January 1, 2016. (Viewed online, 31st January 2017) https://www.cipd.co.uk/knowledge/fundamentals/people/performance/competency-factsheet\#6371

CIPD (2016). Performance management: an introduction. (Viewed online, 23rd December 2017) https://www.cipd.co.uk/knowledge/fundamentals/people/performance/factsheet

Draganidis, F., \& Mentzas, G. (2006). Competency based management: a review of systems and approaches. Information Management \& Computer Security, 14(1), 51-64.

Huselid, M. A. (1995). The impact of human resource management practices on turnover, productivity, and corporate financial performance. Academy of Management Journal, 38(3), 635-672.

June, S., \& Mahmood, R. (2011). The Relationship between Role Ambiguity, Competency and PersonJob Fit With the Job Performance of Employees in the Service Sector SMEs in Malaysia. Business Management Dynamics, 1(2), 79-98. 
Kearns, P. (2001). Generic skills for the new economy: A review of research relating to generic skills, NCVER, Adelaide.

Kelliher, C., \& Perrett, G. (2001). Business strategy and approaches to HRM-A case study of new developments in the United Kingdom restaurant industry. Personnel Review, 30(4), 421-437.

Koch, M. J., \& McGrath, R. G. (1996). Improving labor productivity: Human resource management policies do matter. Strategic Management Journal, 17(5), 335-354.

Lawler, E. E., \& Mohrman, S. A. (2003). HR as a Strategic Partner: What Does It Take to Make It Happen? Human Resource Planning, 26, 15-29.

Lepak, D. P., \& Snell, S. A. (1999). The human resource architecture: Toward a theory of human capital allocation and development. Academy of Management Review, 24(1), 31-48.

Lin, X., \& Tang, H. (2016). A Framework for Human Resource Configurations in Knowledge-intensive Organizations. International Journal of Business Administration, 7(1), 1.

McClelland, D. C. (1973). Testing for competence rather than for 'intelligence', American Psychologist, 28(1) 1-14.

Misra, Y., \& Sharma, V. (2017). An Exploratory Study on Business Strategy, Competency and Firm Performance, SUMEDHA Journal of Management, 6(2).

Mohd Noor, K. B., \& Dola, K. (2009). Job Competencies for Malaysian Managers in Higher Education Institution. Asian Journal of Management and Humanity Sciences, 4(4), 226-240.

Rubin, H. J., \& Rubin, I. S. (2005). Qualitative Interviewing - The Art of Hearing Data. 2. Edition, Sage Publications, Thousand Oaks, London, New York.

Selznick, Philip (1957). Leadership in administration. New York: Harper \& Row.

Strebler, M. T., Thomson, M., \& Heron, P. (1997). Skills, Competencies and Gender: Issues for Pay and Training. Brighton: Institute for Employment Studies, Report 333.

\section{The Author}

Dr Kalama Adefe is a Fellow of the Higher Education Academy. He holds a master's degree in Human Resource Management and a Doctor of Philosophy degree in Business and Management from the University of Sunderland. His research interest includes Competencies, SHRM, and organisational Performance.

Dr Derek Watson, is a Senior Fellow of the Higher Education Academy. He is the founder of the University's Business Clinic and leads the University's Doctoral Research Programme. His research focuses on academic-industry innovative collaboration and investigating the impact of knowledge exchange on practice in both the classroom and the workplace.

Joyce Liddle is Professor of Public Leadership \& Innovation at Newcastle Business School, UK and visiting Professor at Tor Vergata, Rome and Edge Hill, UK. She is a Fellow of the British Academy of Social Science, UK Joint University Council, and Regional Studies Association. Her research interests include public leadership and entrepreneurship, territorial governance, partnerships, and networks. 
